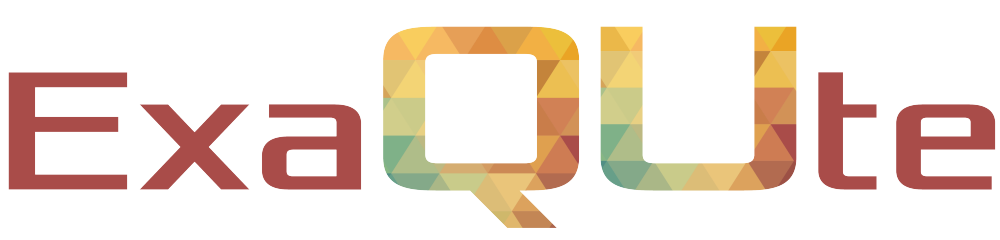

Exascale Quantification of Uncertainties for

Technology and Science Simulation

\title{
D7.1 - DELIVERY OF GEOMETRY AND COMPUTATIONAL MODEL
}

\section{Document information table}

\begin{tabular}{|l|l|}
\hline Contract number: & 800898 \\
\hline Project acronym: & ExaQUte \\
\hline Project Coordinator: & CIMNE \\
\hline Document Responsible Partner: & str.ucture GmbH \\
\hline Deliverable Type: & Other \\
\hline Dissemination Level: & Confidential \\
\hline Related WP \& Task: & WP7 7.1 \\
\hline Status: & V00 \\
\hline
\end{tabular}

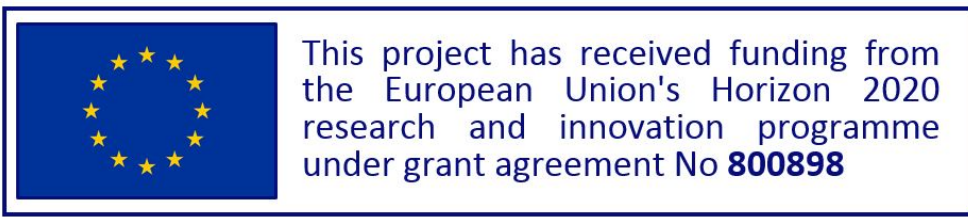




\section{Authoring}

\begin{tabular}{|l|l|l|l|l|}
\hline Prepared by: str.ucture GmbH \\
\hline Authors & Partner & Modified Page/Sections & Version & Comments \\
\hline Alexander Michalski & STR & Complete document & 00 & \\
\hline David Andersson & STR & Complete document & 00 & \\
\hline
\end{tabular}

\section{Change Log}

\begin{tabular}{|l|l|l|}
\hline Versions & Modified Page/Sections & Comments \\
\hline 00 & & Creation of document \\
\hline & & \\
\hline & & \\
\hline
\end{tabular}

\section{Approval}

\section{Aproved by:}
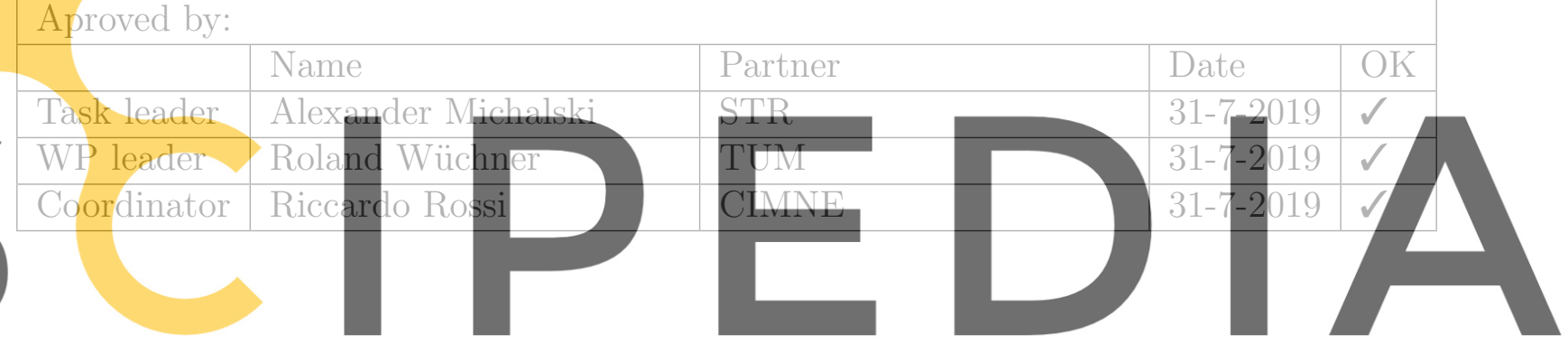

Register for free at https//www.scipedia.com to download the version without the watermark 


\section{Summary}

This document describes the industrial application, on which the developments of the project are implemented, and the CFD set-up. The developments are implemented over six analysis cases with increasing complexity starting from a 2D geometry with mean wind inflow to a 3D geometry with turbulent inflow and real-time shape optimization. The application represents the CAARC tall building model, which has served as a benchmark model for many studies since the 1970's when it was first developed. Base moments (bending and torsional moments) of the building are extracted for validation by comparison of the results with the benchmark study.
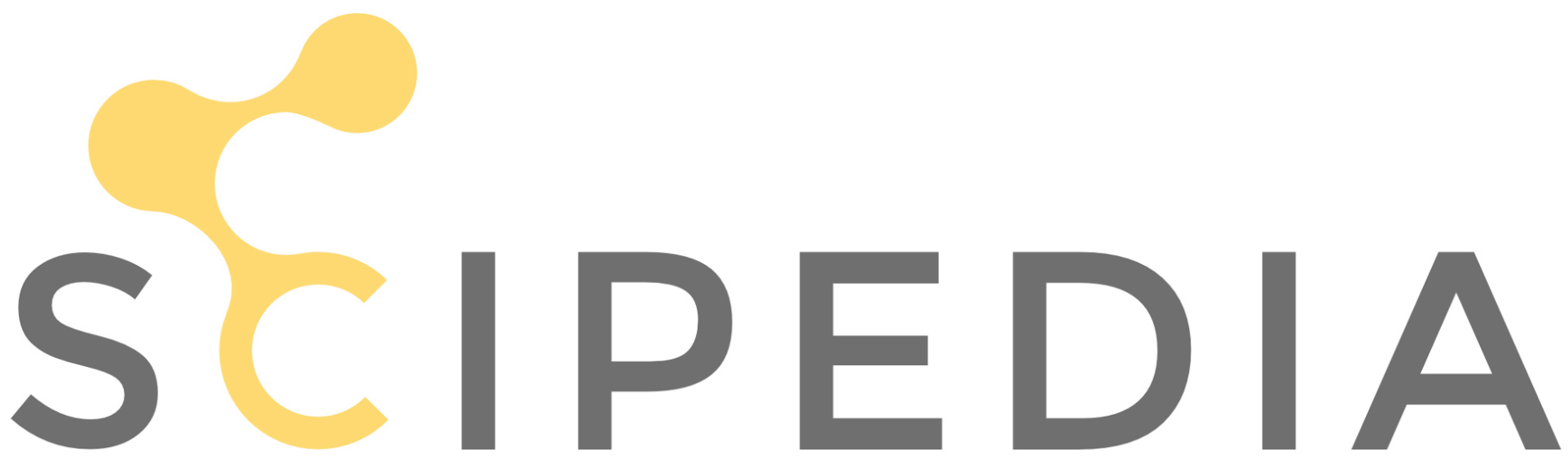

Register for free at https//www.scipedia.com to download the version without the watermark 


\section{Table of contents}

1 Introduction $\quad 7$

1.1 Benchmark study . . . . . . . . . . . . . . . . . . 7

1.2 CAARC standard tall building . . . . . . . . . . . . . . 8

1.3 Target values . . . . . . . . . . . . . . . . . . . . 9

2 CFD set-up $\quad 10$

2.1 Turbulence modelling and inflow conditions . . . . . . . . . . . . . 10

2.2 Wind parameters . . . . . . . . . . . . . . . . . . 10

2.3 Computational domain and orientation . . . . . . . . . . . . . 11

2.4 Boundary conditions . . . . . . . . . . . . . . . . . 13

3 Deliverable 14

A Analysis cases $\quad 15$

A.1 Case $1 \ldots \ldots \ldots \ldots \ldots$

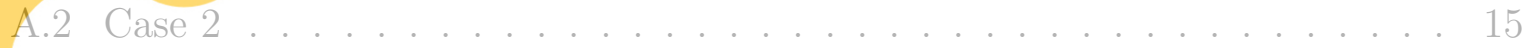

A.3 Case $3 \ldots \ldots \ldots \ldots \ldots \ldots$

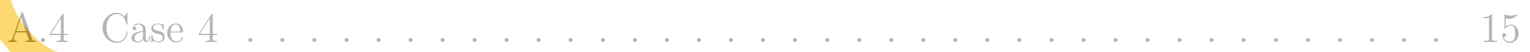
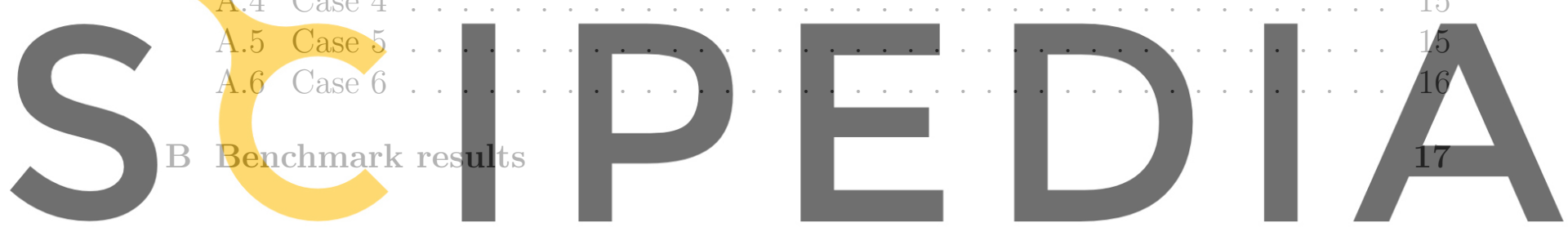

Register for free at https//www.scipedia.com to download the version without the watermark 


\section{List of Figures}

1 Dimensions of the CAARC standard tall building model $[\mathrm{m}] . \ldots$. . . . . . 8

2 Dimensions of computational domain. . . . . . . . . . . . . . 11

3 Local orientation of the building. . . . . . . . . . . . . . . . . . 12

4 Boundary conditions. . . . . . . . . . . . . . . . 13

$5 \quad$ Mean base moments around local $\tilde{X}$-axis for the seven test groups $[3,4] . \quad$. 17

$6 \quad$ Mean base moments around local $\widetilde{Y}$-axis for the seven test groups [3, 4]. . 18

$7 \quad$ Mean base moments around local $\widetilde{Z}$-axis for the seven test groups [3, 4]. . 18

\section{List of Tables}

1 Wind parameters to be used in the study.
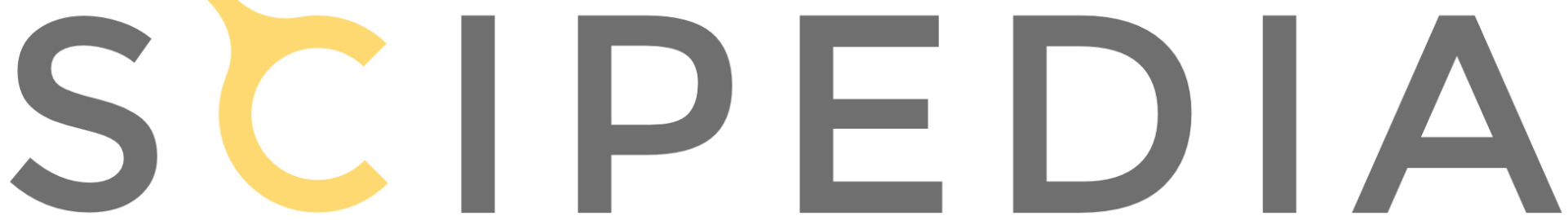

Register for free at https//www.scipedia.com to download the version without the watermark 


\section{Nomenclature / Acronym list}

\begin{tabular}{|l|l|}
\hline Acronym & Meaning \\
\hline CAD & Computer Aided Design \\
\hline CFD & Computational Fluid Dynamics \\
\hline $\mathrm{v}_{\text {ref }}$ & Reference wind speed \\
\hline $\mathrm{z}_{\text {ref }}$ & Reference height \\
\hline$\alpha$ & Power law exponent \\
\hline
\end{tabular}
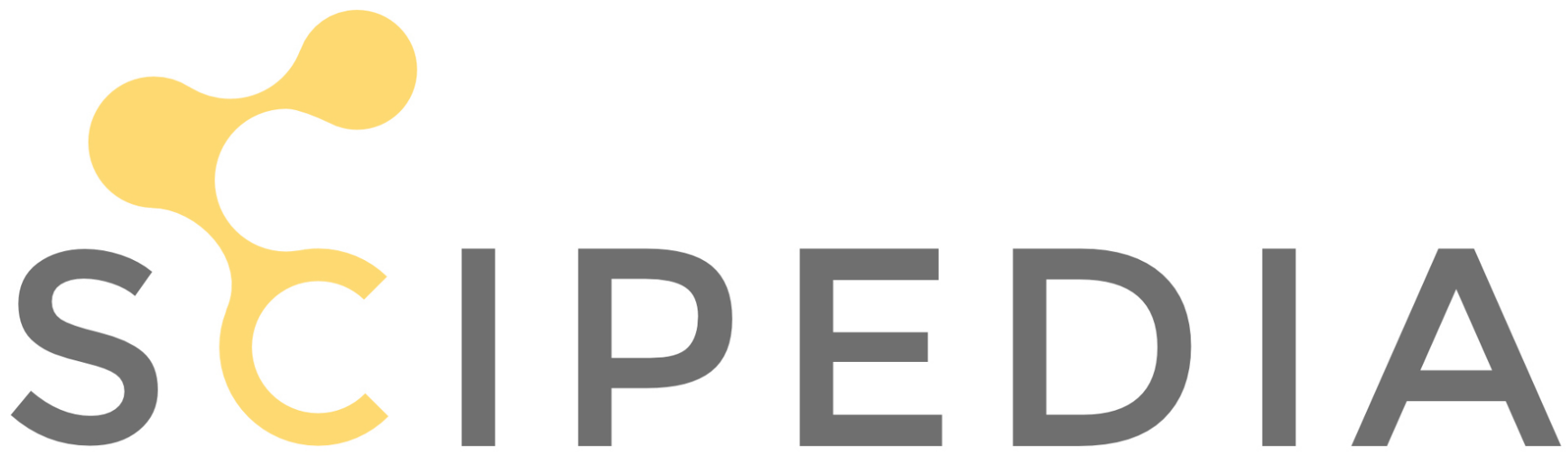

Register for free at https//www.scipedia.com to download the version without the watermark 


\section{Introduction}

There is a great potential applying advanced computational wind engineering methods in the field of high-rise structures, as there is an increasing need worldwide to build more and slender, and hence wind prone, high-rise structures in densely urbanized parts of the world. A high-rise building is therefore chosen as the industrial application, on which the developments of the project are implemented.

\subsection{Benchmark study}

To be able to validate the wind forces on the structure, the numerically obtained results has to be compared with either wind tunnel tests or on-site measurements. In this study the comparative International high-frequency base balance benchmark study [3] will act in this purpose.

The initiative for the benchmark study was taken during a meeting held at the $12^{\text {th }}$ International Conference on Wind Engineering in July 2007 [3]. The study was conducted between the years 2007 and 2011 where eight international wind-tunnel laboratories car-

ried out independent tests and subsequently presented their results for comparison [3].
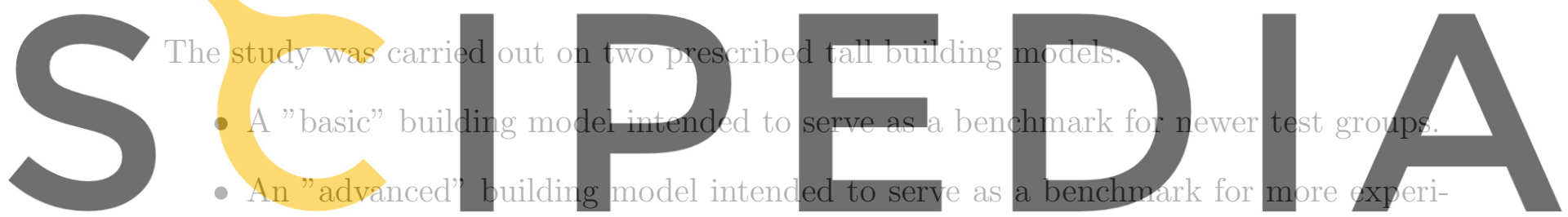

enced test laboratories.

Register for free at https//www.scipedia.com to download the version without the watermark

The former of the two is a metric version of the Commonwealth Advisory Aeronautical

Council (CAARC) standard tall building model $[4]$ which is hereinafter the model used in this study. 


\subsection{CAARC standard tall building}

The CAARC standard tall building model was developed in 1970 [6] for analysis of wind loading on tall buildings. It has since then been one of the more popular high-rise building models for wind tunnel studies, as it originally was developed for, but has in recent times also been used extensively as application for numerical CFD analysis [1].
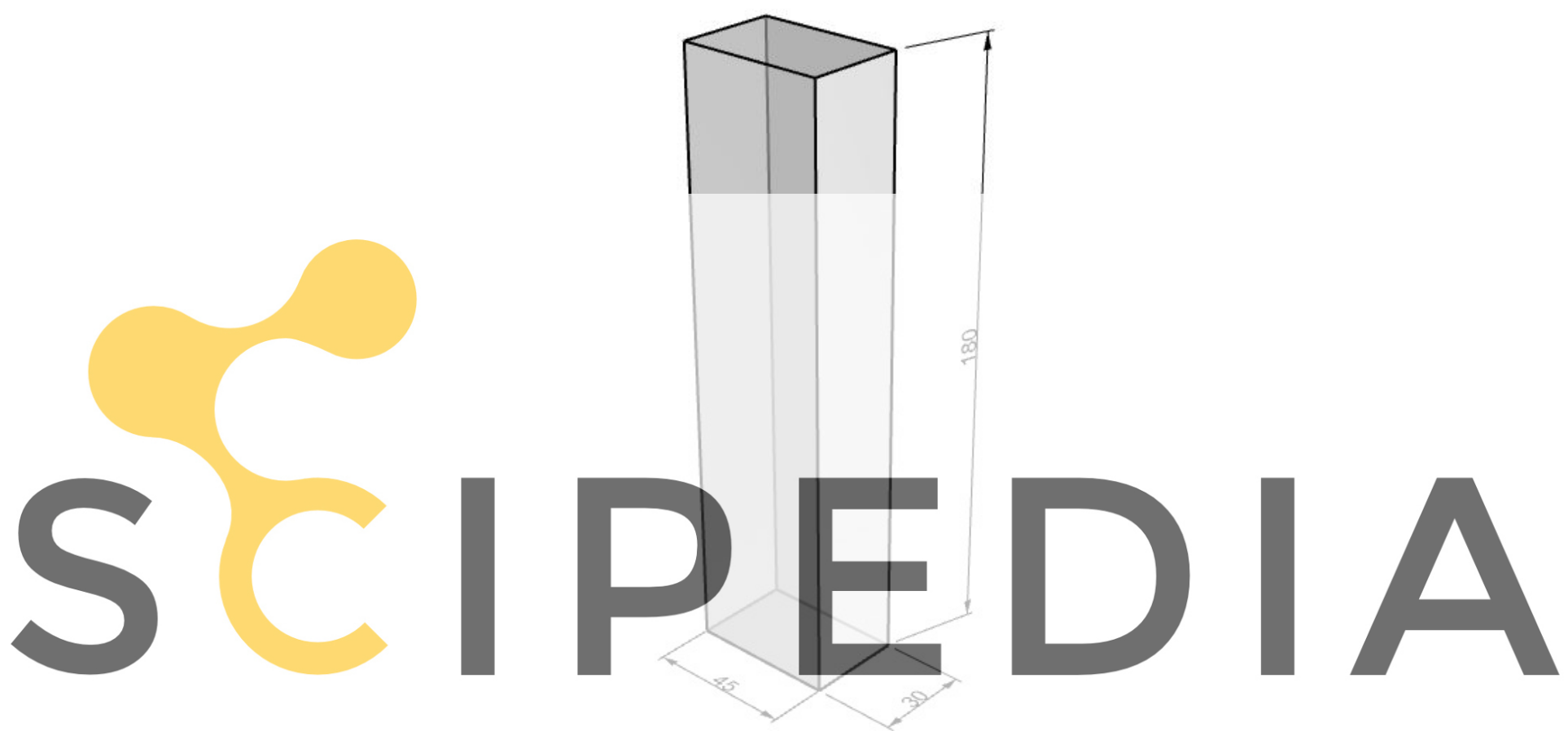

Register for free at https//www.scipedia.com to download the version without the watermark

Figure 1: Dimensions of the CAARC standard tall building model [m]. 


\subsection{Target values}

It is known that only base moments are not sufficient for designing a structure. However, due to the complexity of the developments that are to be implemented the target values are chosen as simple as possible but at the same time sufficient enough to be able to validate the study.

The benchmark study presents resulting mean base moments (bending and torsional moments) of the building, shown in Appendix B. Mean base moments are thus used as target values also in this study.
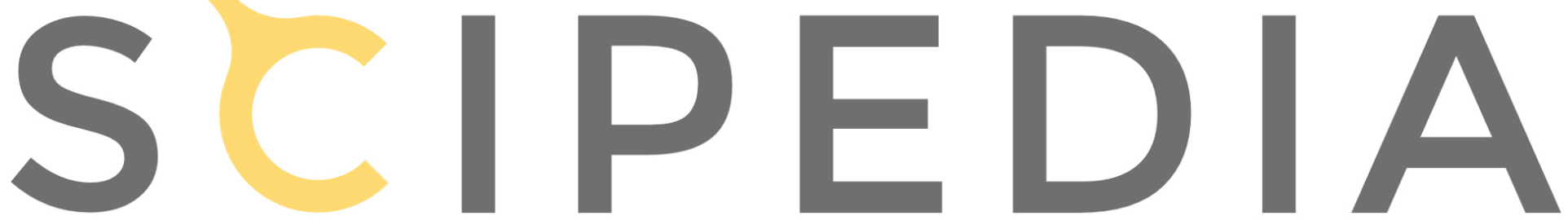

Register for free at https//www.scipedia.com to download the version without the watermark 


\section{CFD set-up}

\subsection{Turbulence modelling and inflow conditions}

The Large-Eddy Simulation (LES) is used throughout the study to model the turbulence.

To model the natural wind conditions at the inlet the velocity boundary condition is separated into one mean wind part and one fluctuating part, described in the equation below.

$$
v_{i}(z, t)=\bar{v}_{i}(z)+v_{i}^{\prime}(z, t)
$$

The mean wind part is generated using the power law (cf. chapter 2.2) and the fluctuating part is generated by an algorithm described by Jakob Mann [5].

\subsection{Wind parameters}

The mean wind profile is generally described by the power law.
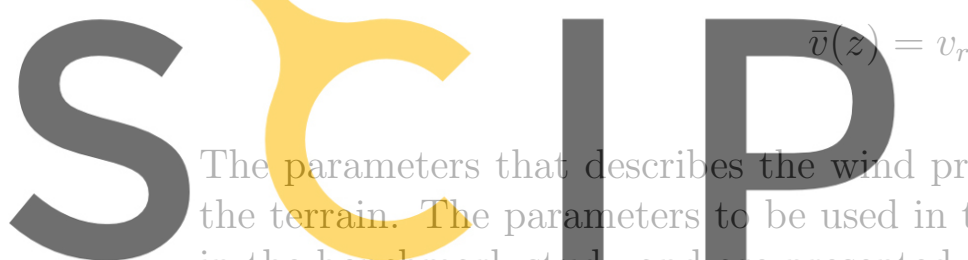

in the benchmark study and at
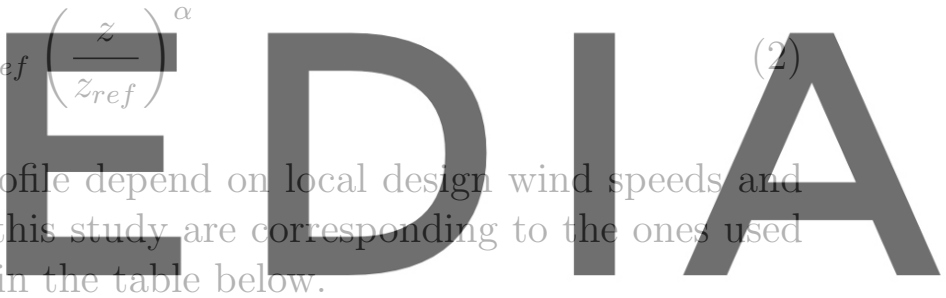

Register for free at https//www.scipedia.com to download the version without the watermark Table 1: Wind parameters to be used in the study.

\begin{tabular}{|l|l|}
\hline Parameter & Value \\
\hline $\mathrm{v}_{\text {ref }}$ & $20[\mathrm{~m} / \mathrm{s}]$ \\
\hline $\mathrm{z}_{\text {ref }}$ & $10[\mathrm{~m}]$ \\
\hline$\alpha$ & 0.25 \\
\hline
\end{tabular}




\subsection{Computational domain and orientation}

It is recommended to place the inlet surface, the lateral surfaces and the top surface $5 \mathrm{H}$ away from the building and the outlet surface $15 \mathrm{H}$ away from the building $(6 \mathrm{H} \times 10 \mathrm{H} \times 20 \mathrm{H})$, where $\mathrm{H}$ is the total height of the building, according to the guidelines of CFD simulations in wind engineering [2].

These recommendations generates a quite big and expensive computational domain, the effects of a smaller computational domain was therefore investigated by Daniels et al. It is stated that the results obtained with a smaller domain $(4 \mathrm{H} \times 8 \mathrm{H} \times 10 \mathrm{H})$ were consistent with the results obtained with the bigger domain [1], the smaller domain was thus used throughout their study.

With the aim of doing the analysis more economic the size of the computational domain of the present study will follow those used by Daniels et al.

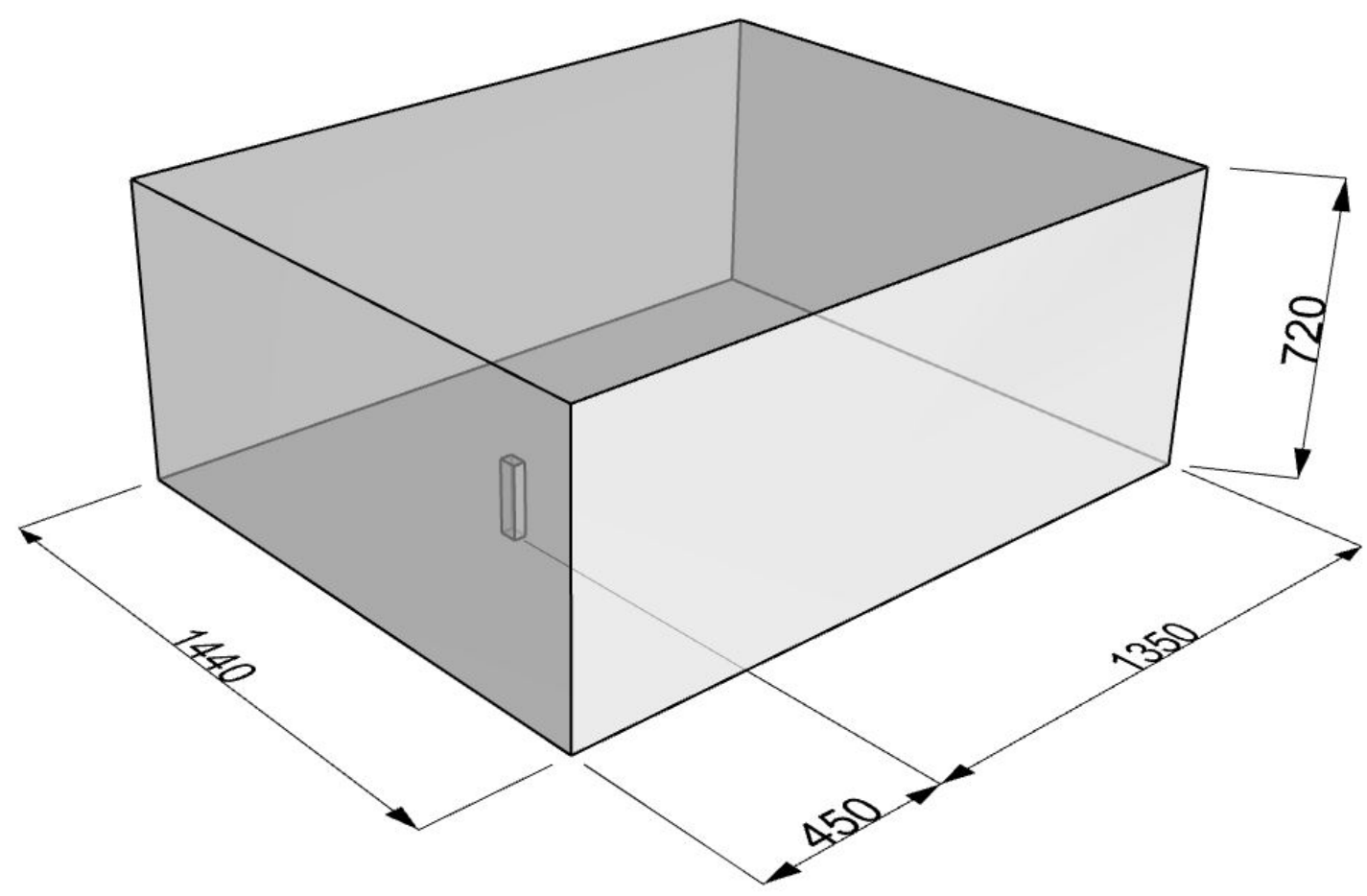

Figure 2: Dimensions of computational domain. 
The orientation of the building is chosen to align with that from the benchmark study (cf. figure 3).

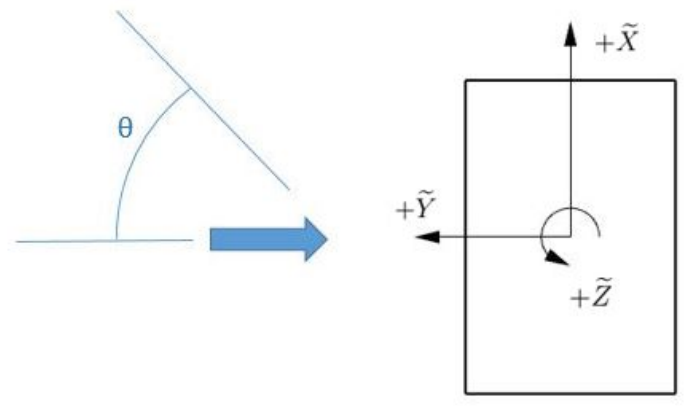

Figure 3: Local orientation of the building. 


\subsection{Boundary conditions}

The boundary conditions are chosen in line with the benchmark study. The lateral surfaces and the top surface are set to symmetry-planes and a no-slip condition is assigned on the bottom of the domain and on the walls of the CAARC building $[1,3]$.

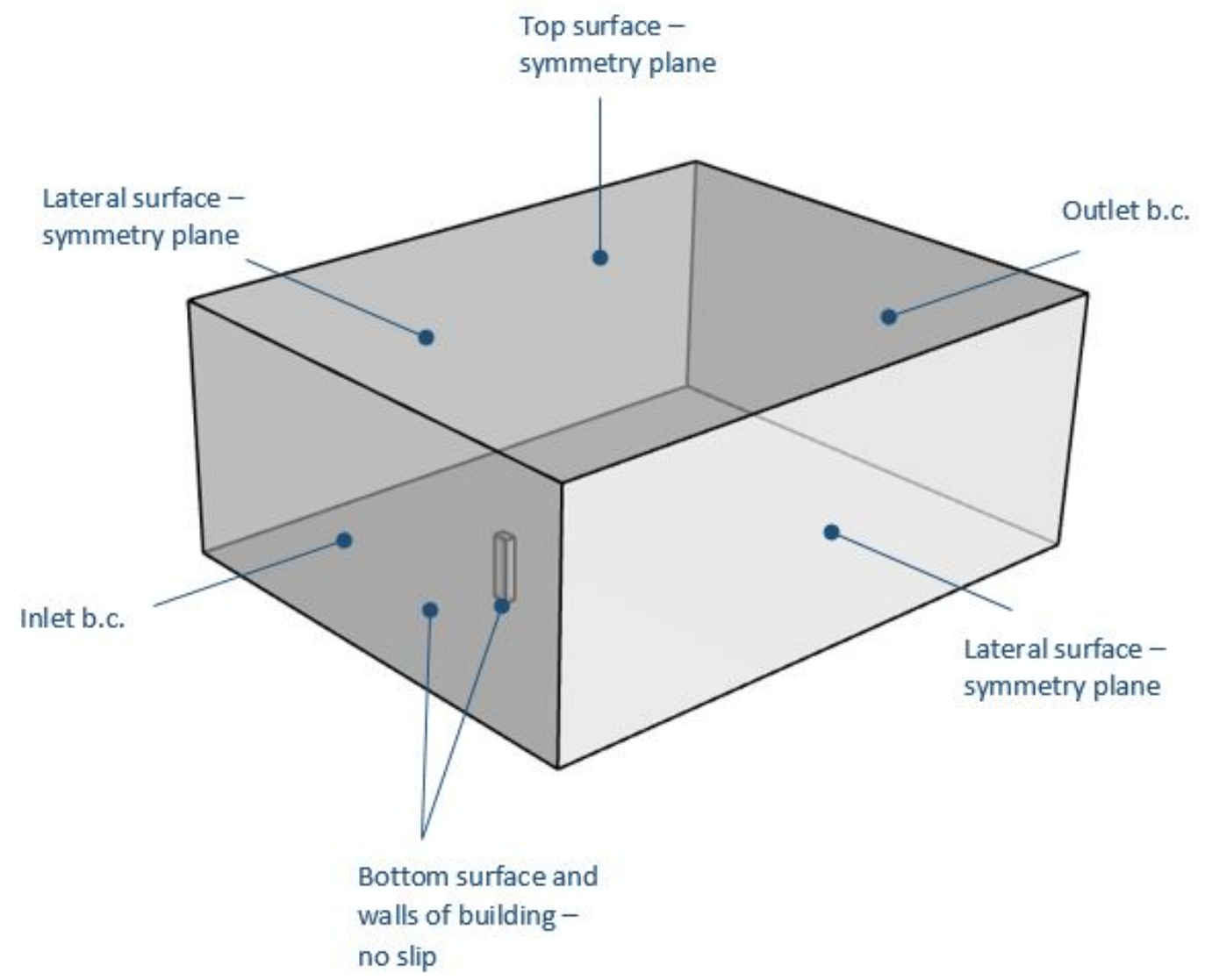

Figure 4: Boundary conditions. 


\section{Deliverable}

A CAD model of the CAARC building can be delivered to the PO if required. 


\section{Appendix A Analysis cases}

The complexity of the analysis is gradually increased over six analysis cases where the basic set-up for each individual case is presented below.

\section{A.1 Case 1}

\begin{tabular}{|l|l|}
\hline Geometry: & $2 \mathrm{D} 30 \times 180[\mathrm{~m}]$ \\
\hline Computational domain: & $1080 \times 3600[\mathrm{~m}]$ \\
\hline Inflow conditions: & Mean wind profile \\
\hline Morphing: & None \\
\hline Target value(s): & Base moment $M_{\tilde{X}}$ \\
\hline
\end{tabular}

\section{A.2 Case 2}

\begin{tabular}{|l|l|}
\hline Geometry: & 2D 30x180 [m] \\
\hline Computational domain: & 1080x3600 [m] \\
\hline Inflow conditions: & Turbulent wind profile (Mann model) \\
\hline Morphing: & None \\
\hline Target value(s): & Base moment $M_{\tilde{X}}$ \\
\hline
\end{tabular}

\section{A.3 Case 3}

\begin{tabular}{|c|c|}
\hline Geometry: & $3 \mathrm{D} 30 \times 45 \times 180[\mathrm{~m}]$ \\
\hline Computational domain: & 1080x1800x3600 [m] \\
\hline Inflow conditions: & Mean wind profile \\
\hline Morphing: & None \\
\hline Target value(s): & Base moments $M_{i}(i=\widetilde{X}, \widetilde{Y}, \widetilde{Z})$ \\
\hline
\end{tabular}

\section{A.4 Case 4}

\begin{tabular}{|l|l|}
\hline Geometry: & $3 \mathrm{D} 30 \times 45 \times 180[\mathrm{~m}]$ \\
\hline Computational domain: & $1080 \times 1800 \times 3600[\mathrm{~m}]$ \\
\hline Inflow conditions: & Mean wind profile \\
\hline Morphing: & Real-time shape optimization \\
\hline Target value(s): & Base moments $M_{i}(i=\widetilde{X}, \widetilde{Y}, \widetilde{Z})$ \\
\hline
\end{tabular}

\section{A.5 Case 5}

\begin{tabular}{|c|c|}
\hline Geometry: & $3 \mathrm{D} 30 \times 45 \times 180[\mathrm{~m}]$ \\
\hline Computational domain: & 1080x1800x3600 [m] \\
\hline Inflow conditions: & Turbulent wind profile (Mann model) \\
\hline Morphing: & None \\
\hline Target value(s): & Base moments $M_{i}(i=\widetilde{X}, \widetilde{Y}, \widetilde{Z})$ \\
\hline
\end{tabular}




\section{A. 6 Case 6}

\begin{tabular}{|l|l|}
\hline Geometry: & 3D 30x45x180 $[\mathrm{m}]$ \\
\hline Computational domain: & 1080x1800x3600 [m] \\
\hline Inflow conditions: & Turbulent wind profile (Mann model) \\
\hline Morphing: & Real-time shape optimization \\
\hline Target value(s): & Base moments $M_{i}(i=\widetilde{X}, \widetilde{Y}, \widetilde{Z})$ \\
\hline
\end{tabular}




\section{Appendix B Benchmark results}

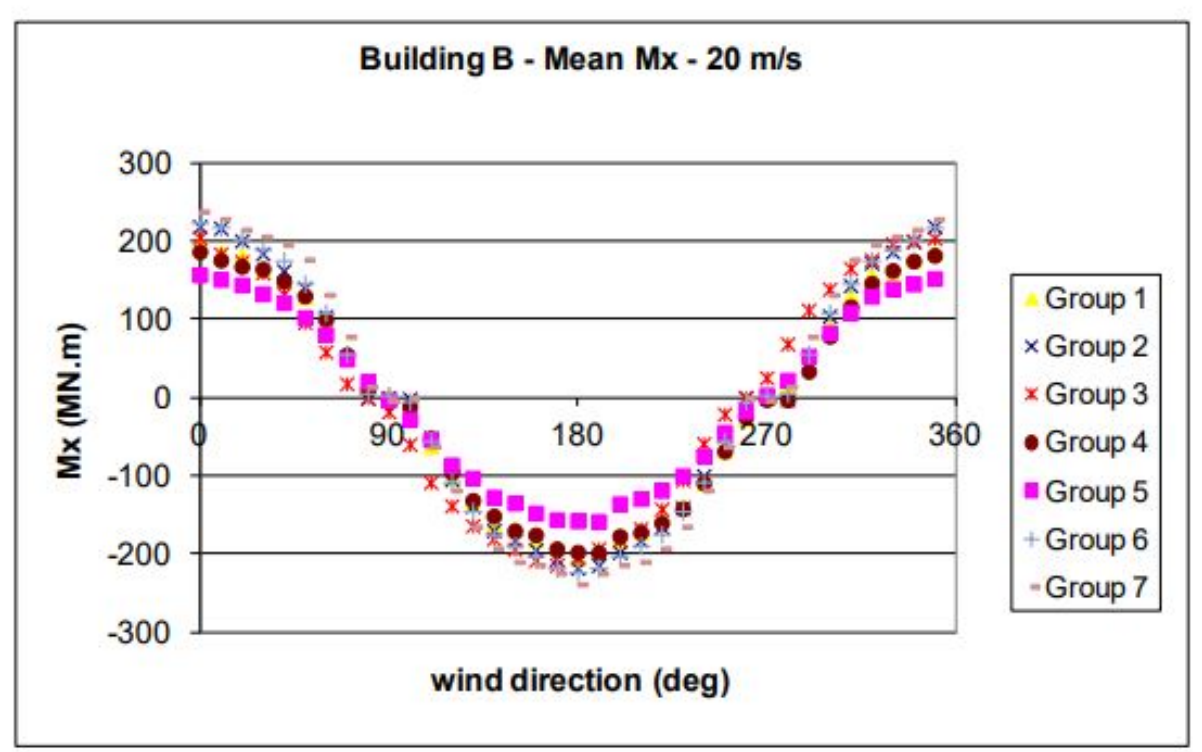

Figure 5: Mean base moments around local $\widetilde{X}$-axis for the seven test groups [3, 4]. 


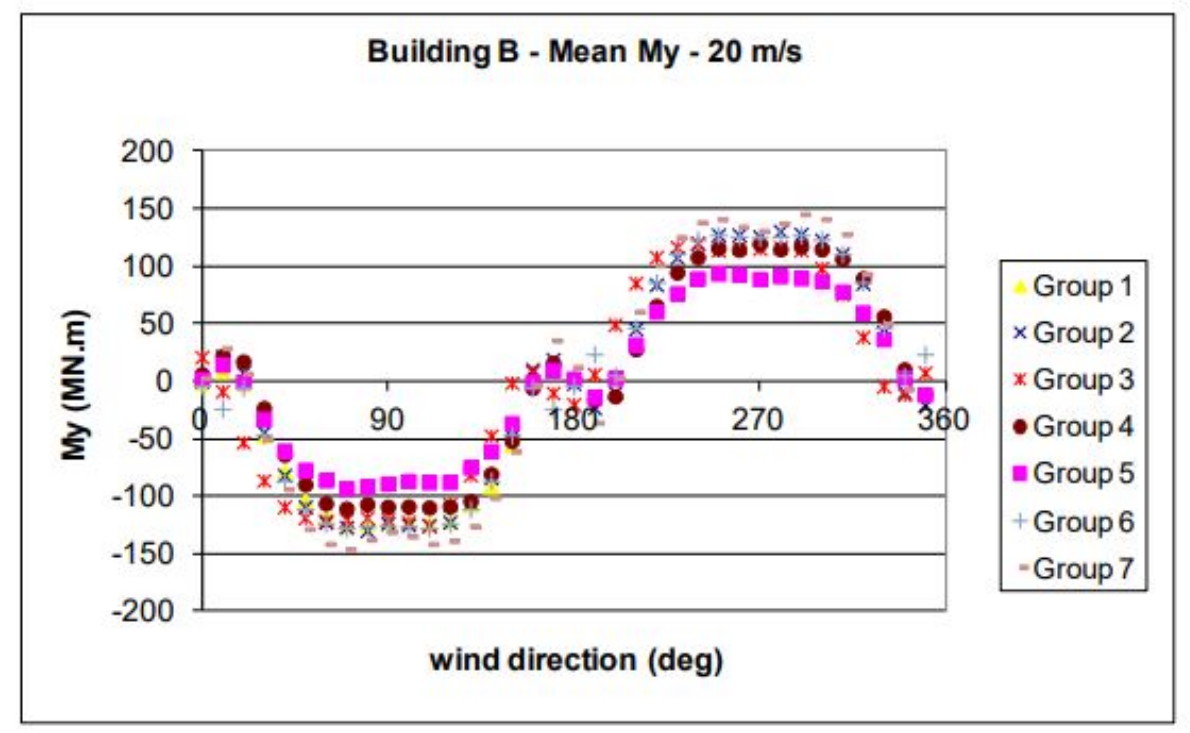

Figure 6: Mean base moments around local $\widetilde{Y}$-axis for the seven test groups [3, 4].

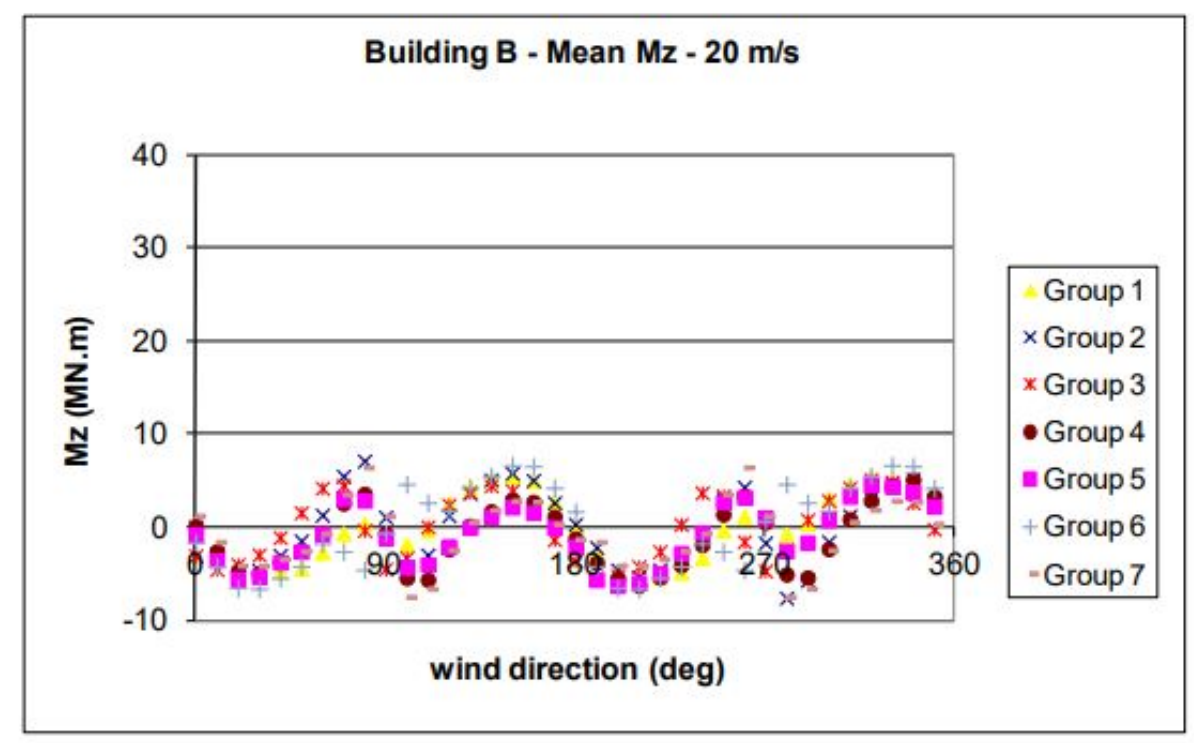

Figure 7: Mean base moments around local $\widetilde{Z}$-axis for the seven test groups $[3,4]$. 


\section{References}

[1] S. Daniels et al. Peak loading and surface pressure fluctuations of a tall building model. Journal of wind engineering and industrial aerodynamics, 120, 2013.

[2] J. Franke et al. Recommendations on the use of CFD in wind engineering. Cost action $C, 14,2004$.

[3] J. Holmes et al. International high-frequency base balance benchmark study. Wind and Structures, 18:457-471, 2014.

[4] IAWE et al. Benchmark Buildings for an International HFBB Comparison. International Accosiation for Wind Engineering, 2012.

[5] J. Mann. Wind field simulation. Probabilistic Engineering Mechanics, 13:269-282, 1998.

[6] R. Wardlaw et al. A standard tall building model for the comparison of simulated natural winds in wind tunnel. CAARC, CC 662m Tech 25, 1970. 